\title{
Antiplatelet Effects of Flavonoids Mediated by Inhibition of Arachidonic Acid Based Pathway
}

Authors

Affiliations
Jana Karlíčková ${ }^{1}$, Michal Ř́ha ${ }^{2}$, Tomáš Filipský ${ }^{2}$, Kateřina Macáková ${ }^{1}$, Radomír Hrdina ${ }^{2}$, Přemysl Mladěnka ${ }^{2}$

${ }^{1}$ Department of Pharmaceutical Botany and Ecology, Faculty of Pharmacy in Hradec Králové, Charles University in Prague, Hradec Králové, Czech Republic

${ }^{2}$ Department of Pharmacology and Toxicology, Faculty of Pharmacy in Hradec Králové, Charles University in Prague, Hradec Králové, Czech Republic

\author{
Key words \\ - aggregation \\ - arachidonic acid \\ - cyclooxygenase \\ - flavonoid \\ - platelet \\ - thromboxane
}

\section{Abstract \\ $\nabla$}

Flavonoids, important components of human diet, have been claimed to possess a significant antiplatelet potential, in particular due to their effects on the arachidonic acid cascade. Due to variable and incomplete results, this study was aimed at delivering a detailed analysis of the effects of 29 structurally relevant, mainly natural flavonoids on three consecutive steps of the arachidonic acid cascade.

Only the isoflavonoids genistein and daidzein were shown to possess a marked cyclooxygenase-1 inhibitory activity, which was higher than that of acetylsalicylic acid using the isolated ovine enzyme, and physiologically relevant, although lower than acetylsalicylic acid in human platelets. None of the tested flavonoids possesses an effect on thromboxane synthase in a clinically achiev-

\section{Introduction}

January 5,2015

accepted July 30,2015

Bibliography

Dol http://dx.doi.org/

10.1055/s-0035-1557902

Published online September 21, 2015

Planta Med 2016; 82: 76-83

(c) Georg Thieme Verlag KG Stuttgart · New York .

ISSN 0032-0943

\section{Correspondence}

Assoc. Prof. Přemysl

Mladěnka, Ph.D.

Department of Pharmacology and Toxicology

Faculty of Pharmacy in Hradec Králové

Charles University in Prague

Heyrovského 1203

50005 Hradec Králové

Czech Republic

Phone: + 420495067295

Fax: + 420495067170

mladenkap@faf.cuni.cz

\section{$\nabla$}

Platelets are essential components of the human blood responsible for rapid blood coagulation during injuries. On the other hand, excessive platelet aggregation is associated with cardiovascular diseases, in particular with the risk of serious or fatal coronary heart disease. Because both decreased and increased platelet aggregation are associated with pathological states, the process of aggregation has to be tightly controlled. The homeostasis is very complex and scientists have not been able to precisely define the process in all aspects up to date [1]. There are several proaggregatory factors which enhance thrombus formation. The central role in this cascade appears to be associated with the release of AA from the cytoplasmatic membrane and its transformation into prostaglandin $\mathrm{H}_{2}$ by platelet COX-1, with further metabolism into thromboxane $A_{2}$ by platelet thromboxane synthase. This process is stimulated able concentration. Contrarily, many flavonoids, particularly those possessing an isolated 7-hydroxyl group and/or a 4'-hydroxyl group, acted as antagonists on thromboxane receptors. Interestingly, the substitution of the free 7-hydroxyl group by glucose might not abolish the activity. In conclusion, the consumption of few flavonoids in a diet, particularly of the isoflavonoids genistein and daidzein, may positively influence platelet aggregation.

\section{Abbreviations \\ $\nabla$ \\ AA: $\quad$ arachidonic acid \\ ASA: acetylsalicylic acid \\ COX-1: cyclooxygenase-1 \\ EDTA: ethylenediaminetetraacetic acid \\ PRP: $\quad$ platelet rich plasma}




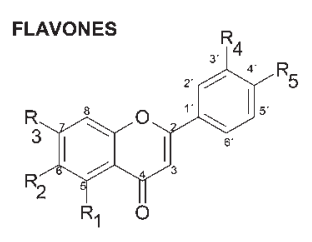

\begin{tabular}{|l|c|c|c|c|c|}
\hline \multicolumn{1}{|c|}{ flavones } & $\mathbf{R}_{\mathbf{1}}$ & $\mathbf{R}_{\mathbf{2}}$ & $\mathbf{R}_{\mathbf{3}}$ & $\mathbf{R}_{4}$ & $\mathbf{R}_{5}$ \\
\hline flavone & $\mathrm{H}$ & $\mathrm{H}$ & $\mathrm{H}$ & $\mathrm{H}$ & $\mathrm{H}$ \\
\hline 5-hydroxyflavone & $\mathrm{OH}$ & $\mathrm{H}$ & $\mathrm{H}$ & $\mathrm{H}$ & $\mathrm{H}$ \\
\hline 7-hydroxyflavone & $\mathrm{H}$ & $\mathrm{H}$ & $\mathrm{OH}$ & $\mathrm{H}$ & $\mathrm{H}$ \\
\hline chrysin & $\mathrm{OH}$ & $\mathrm{H}$ & $\mathrm{OH}$ & $\mathrm{H}$ & $\mathrm{H}$ \\
\hline apigenin & $\mathrm{OH}$ & $\mathrm{H}$ & $\mathrm{OH}$ & $\mathrm{H}$ & $\mathrm{OH}$ \\
\hline apigenin-7-glucoside & $\mathrm{OH}$ & $\mathrm{H}$ & $\mathrm{O}-\mathrm{Glc}$ & $\mathrm{H}$ & $\mathrm{OH}$ \\
\hline Iuteolin & $\mathrm{OH}$ & $\mathrm{H}$ & $\mathrm{OH}^{-}$ & $\mathrm{OH}$ & $\mathrm{OH}$ \\
\hline negletein & $\mathrm{OH}$ & $\mathrm{OH}$ & $\mathrm{OCH}_{3}$ & $\mathrm{H}$ & $\mathrm{H}$ \\
\hline baicalein & $\mathrm{OH}$ & $\mathrm{OH}$ & $\mathrm{OH}$ & $\mathrm{H}$ & $\mathrm{H}$ \\
\hline baicalin & $\mathrm{OH}$ & $\mathrm{OH}$ & $\mathbf{O}-\mathrm{Glu}$ & $\mathrm{H}$ & $\mathrm{H}$ \\
\hline mosloflavone & $\mathrm{OH}$ & $\mathrm{OCH}_{3}$ & $\mathrm{OCH}_{3}$ & $\mathrm{H}$ & $\mathrm{H}$ \\
\hline diosmin & $\mathrm{OH}$ & $\mathrm{H}$ & $\mathbf{O}$-Glc-Rha & $\mathrm{OH}$ & $\mathbf{O C H}_{3}$ \\
\hline
\end{tabular}

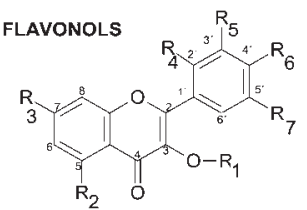

\begin{tabular}{|l|c|c|c|c|c|c|c|}
\hline \multicolumn{1}{|c|}{ ftavonols } & $\mathrm{R}_{1}$ & $\mathrm{R}_{2}$ & $\mathrm{R}_{3}$ & $\mathrm{R}_{4}$ & $\mathbf{R}_{5}$ & $\mathbf{R}_{6}$ & $\mathrm{R}_{7}$ \\
\hline 3-hydroxyflavone & $\mathrm{H}$ & $\mathrm{H}$ & $\mathrm{H}$ & $\mathrm{H}$ & $\mathrm{H}$ & $\mathrm{H}$ & $\mathrm{H}$ \\
\hline kaempferol & $\mathrm{H}$ & $\mathrm{OH}$ & $\mathrm{OH}$ & $\mathrm{H}$ & $\mathrm{H}$ & $\mathrm{OH}$ & $\mathrm{H}$ \\
\hline quercetin & $\mathrm{H}$ & $\mathrm{OH}$ & $\mathrm{OH}$ & $\mathrm{H}$ & $\mathrm{OH}$ & $\mathrm{OH}$ & $\mathrm{H}$ \\
\hline morin & $\mathrm{H}$ & $\mathrm{OH}$ & $\mathrm{OH}$ & $\mathrm{OH}$ & $\mathrm{H}$ & $\mathrm{OH}$ & $\mathrm{H}$ \\
\hline myricetin & $\mathrm{H}$ & $\mathrm{OH}$ & $\mathrm{OH}$ & $\mathrm{H}$ & $\mathrm{OH}$ & $\mathrm{OH}$ & $\mathrm{OH}$ \\
\hline rutin & $\mathrm{Glc-}-\mathrm{Hha}$ & $\mathrm{OH}$ & $\mathrm{OH}$ & $\mathrm{H}$ & $\mathrm{OH}$ & $\mathrm{OH}$ & $\mathrm{H}$ \\
\hline troxerutin & $\mathrm{Glc}-\mathrm{Rha}$ & $\mathrm{OH}$ & $\mathrm{O}-\mathrm{C}_{2} \mathrm{H}_{4}-\mathrm{OH}$ & $\mathrm{H}$ & $\mathrm{O}-\mathrm{C}_{2} \mathrm{H}_{4}-\mathrm{OH}$ & $\mathrm{O}-\mathrm{C}_{2} \mathrm{H}_{4}-\mathrm{OH}$ & $\mathrm{H}$ \\
\hline
\end{tabular}

Fig. 1 Chemical structure of flavonoids tested in this study. Glc: glucose, Rha: rhamnose, Glu: glucuronic acid.

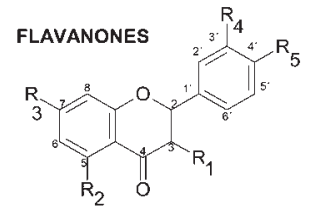

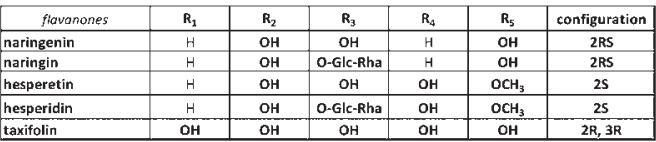

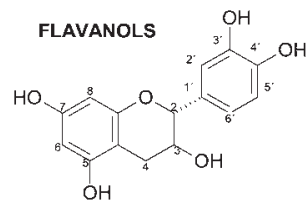

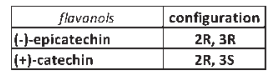

ISOFLAVONES<smiles>[R]c1cc([R])c2c(=O)c(-c3ccc(O)cc3)coc2c1</smiles>

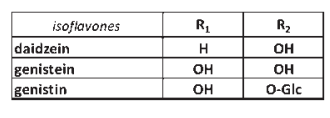

gen, AA, thromboxane receptor agonist U-46619, ADP, and epinephrine [6-10]. The data on thrombin-induced aggregation are controversial, some claim that flavonoids have no effect $[9,11]$, other report positive effects [12]. Additionally, the inhibition of platelet aggregation by flavonoids is a reversible process [9], which is another important factor when considering possible side effects of the current antiplatelet therapy. Although many mechanisms responsible for antiplatelet effects have been proposed [13], only a few are documented by published studies. In particular, their effects on the AA-based aggregation cascade are well documented $[10,14,15]$ but there are several discrepancies ensuing from the use of different protocols (e.g., animal or human platelets, different analytical procedures, use of washed platelets, platelets in plasma, or in the whole blood). Nevertheless, flavonoids may potentiate the effects of ASA via different mechanisms of action [15].

A comprehensive investigation between the flavonoid structure and the effects on the AA cascade including COX-1, thromboxane synthase and thromboxane receptors is still missing. In addition, the effects on thromboxane synthase have been analyzed only indirectly so far. Therefore, this study was aimed at delivering a detailed analysis of 29 flavonoids ( Fig. 1), representing the most commonly found natural flavonoids, and some relevant synthetic congeners in order to establish structure-activity relationship on three consecutive steps of the AA-based platelet aggregation using human platelets.

\section{Results}

Initially, all flavonoids were tested for their possible effects on the inhibition of ovine COX- 1 in a concentration of $100 \mu \mathrm{M}$ and compared to ASA. ASA was moderately active at this concentration, the isoflavones genistein and daidzein were more potent inhibitors $(p<0.01)$, while all other flavonoids were essentially inactive ( $\odot$ Fig. 2A). Considering these surprising results, we retested ASA and the active isoflavonoids for their concentration-dependent effects. Herein, genistein was more potent at lower concentration again but comparable to ASA in higher concentrations. In the case of daidzein, a threshold effect at about $40 \%$ was found ( Fig. 2B). To ascertain if this could be valid for humans, human platelet suspension in plasma was used. In these physiological conditions, ASA showed an excellent effect in units of $\mu \mathrm{M}$ and completely inhibited COX-1 in higher concentrations. Both isoflavonoids were significantly less active, they did not reach full inhibition even at high, pharmacologically unachievable, concentrations but their activity in units of $\mu \mathrm{M}$ could have a real clinical relevance ( Fig. $\mathbf{2 C}$ ). The activities of daidzein and genistein were similar in this set of experiments.

The second step of the AA cascade is the transformation of prostaglandin $\mathrm{H}_{2}$ into thromboxane $\mathrm{A}_{2}$ via thromboxane synthase. All flavonoids were tested for their effect on this enzyme and compared to the known inhibitor 1-benzylimidazol. At the concentration of $100 \mu \mathrm{M}$, only three flavonoids showed more than $25 \%$ inhibition, but all of them were clearly less potent than $25 \mu \mathrm{M}$ of 1-benzylimidazole ( Fig. 3A). These partly active flavonoids, 7- 


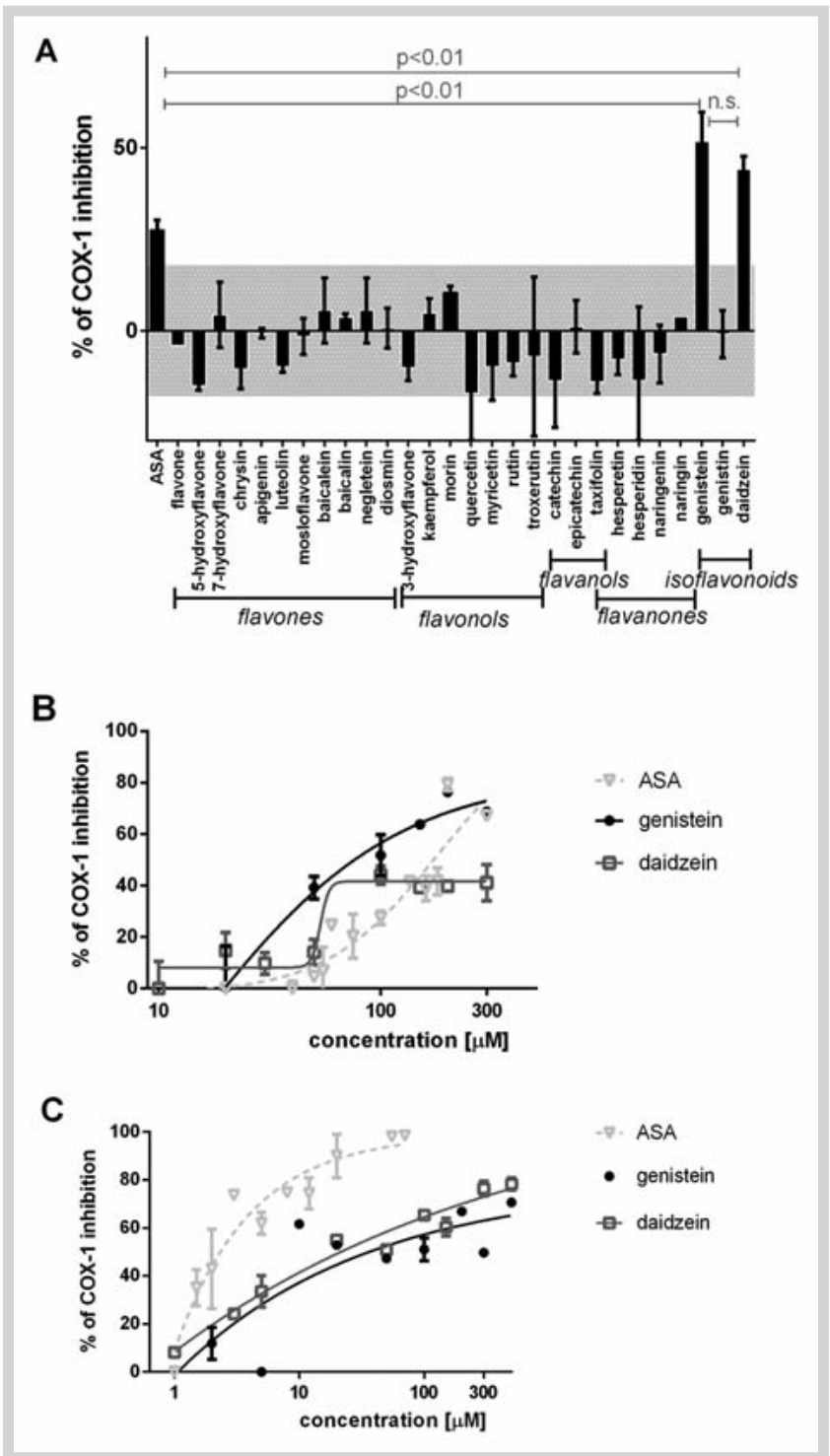

Fig. 2 Effects of flavonoids and ASA on COX-1. A Comparison of the effects of all tested flavonoids on ovine COX-1. Grey area shows the error of the method. Compounds were tested at a concentration of $100 \mu \mathrm{M}$, several flavonoids were retested at higher concentrations, too (7-hydroxyflavone, taxifolin, luteolin, hesperetin, luteolin and taxifolin at $200 \mu \mathrm{M}$ and troxerutin at $400 \mu \mathrm{M})$. B Concentration-effect curves for effective isoflavonoids and ASA on inhibition of ovine COX-1. C Concentration-effect curves for effective isoflavonoids and ASA on inhibition of human plaletet COX-1 in plasma.

hydroxyflavone, apigenin and epicatechin, were additionally tested for a concentration-dependent effect. From these data (O Fig. 3B) it was clear that all three flavonoids were similarly active, and were able to markedly block the enzyme at concentrations which are pharmacologically not relevant, and were more than about 1 order less efficient ( $\mathrm{IC}_{50}$ in the range of 151 to $226 \mu \mathrm{M}$ ) compared to 1-benzylimidazol with an $\mathrm{IC}_{50}$ of $8 \pm 1 \mu \mathrm{M}$. The last well-known part of the aggregation cascade is the activation of thromboxane $\mathrm{A}_{2}$ receptors. In this assay, we used the stable thromboxane $A_{2}$ receptor agonist U-46619. Again, all flavonoids were tested. Notwithstanding the equal platelet concentration used in this study, the effect of U-46619 on platelet aggregation was highly variable, and therefore, we used a two-step cali-

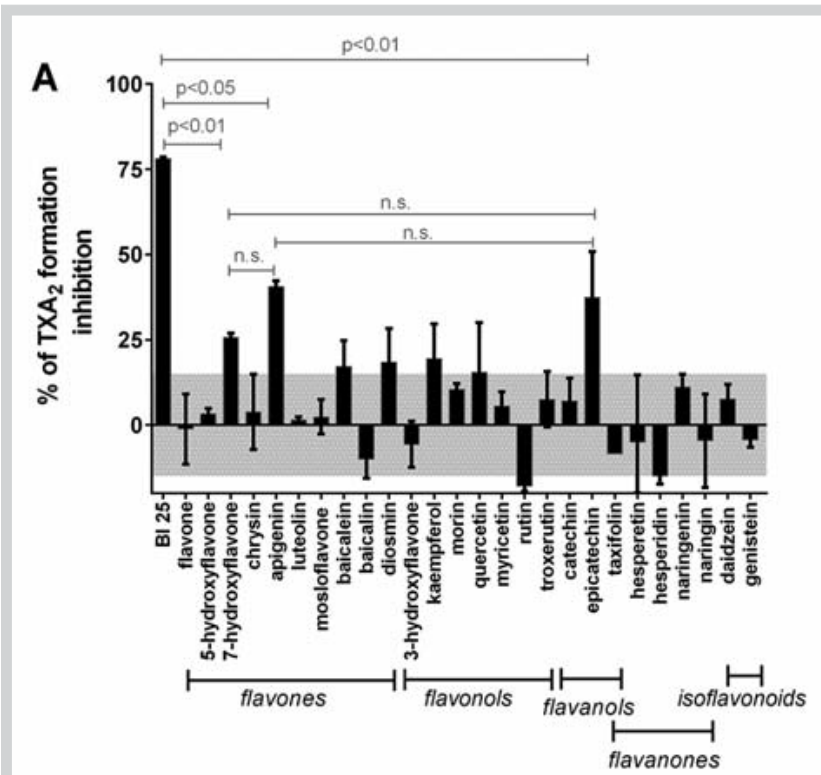

B

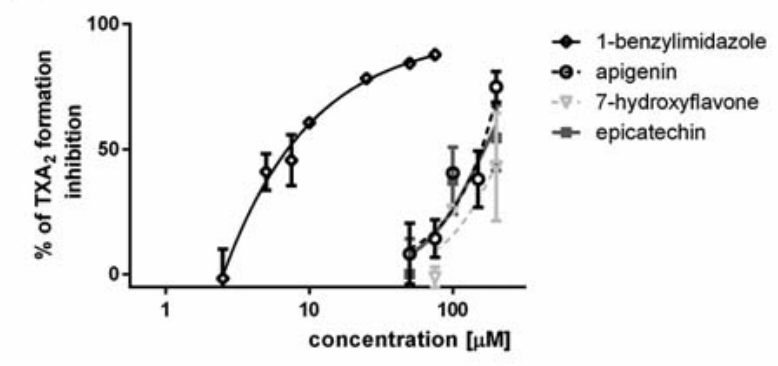

Fig. 3 Effects of flavonoids and 1-benzylimidazol on thromboxane synthase. A Comparison of all compounds at the concentration of $100 \mu \mathrm{M}$. For comparison, $25 \mu \mathrm{M}$ of 1-benzylimidazol (BI 25) is shown. Grey area means the error of the method. All partly active flavonoids were less potent than 1-benzyimidazol but there were no significant differences among them. B Concentration-effect curves of partly active flavonoids.

bration in order to ascertain reproducibility of the results: first, the used concentration of U-46619 in the range of $0.75-1.5 \mu \mathrm{M}$ had to produce more than $90 \%$ aggregation, and second, epicatechin at the concentration of $300 \mu \mathrm{M}$ had to decrease the aggregation to $15-30 \%$. The need of the final concentration of U-46619 in the mentioned range suggests that this analogue has a lower affinity to thromboxane receptors in comparison to the endogenous substrate thromboxane $A_{2}$, but it is well known that it has a much better stability. Due to these reasons, it is not easy to determine the clinical relevance of the inhibitory concentrations. Herein, we tested all compounds up to a concentration of $300 \mu \mathrm{M}$. If no inhibition of platelet aggregation was achieved at this high concentration, the compounds were considered inactive. According to their activity, we divided the flavonoids in 3 classes ( $\bullet$ Table $\mathbf{1}$ ). The active flavonoids were then compared according to two criteria, i.e., $\mathrm{IC}_{50}$ and the effect at a concentration of $100 \mu \mathrm{M}$ ( $\odot$ Fig. 4B,C), because their anti-aggregatory curves had different shapes ( $\odot$ Fig. $4 \mathrm{~A}$ ). Although there were some differences between active flavonoids in terms of $\mathrm{IC}_{50}$ ( $\odot$ Fig. 4B, daidzein and apigenin-7-glucoside were the most potent), there were insignificant differences among all five active flavonoids concerning their effect at a concentration of $100 \mu \mathrm{M}$. 


\begin{tabular}{|c|c|c|}
\hline Class & Effect range & Flavonoids \\
\hline Inefficient & no effect at $300 \mu \mathrm{M}$ & $\begin{array}{l}\text { baicalein, baicalin, flavone, hesperidin, hesperetin, 3-hydroxyflavone, 5-hy- } \\
\text { droxyflavone, mosloflavone, negletein, luteolin, rutin, naringin, taxifolin and } \\
\text { troxerutin }\end{array}$ \\
\hline $\begin{array}{l}\text { Slightly } \\
\text { efficient }\end{array}$ & $\begin{array}{l}\text { effect at } 300 \mu \mathrm{M} \text { but } \\
\text { no effect at } 150 \mu \mathrm{M}\end{array}$ & kaempferol, myricetin, naringenin and quercetin \\
\hline $\begin{array}{l}\text { Moderately } \\
\text { active }\end{array}$ & $\begin{array}{l}\text { effect at } 150 \mu \mathrm{M} \text { but } \\
\text { no effect at } 100 \mu \mathrm{M}\end{array}$ & catechin, diosmin, epicatechin, chrysin, genistin* and morin \\
\hline Active & effect bellow $100 \mu \mathrm{M}$ & apigenin, apigenin-7-glucoside, daidzein, genistein and 7-hydroxyflavone \\
\hline
\end{tabular}

Table 1 Classification of flavonoids according to their potential to inhibit aggregation induced by thromboxane receptor agonist $\mathrm{U}$ 46619.
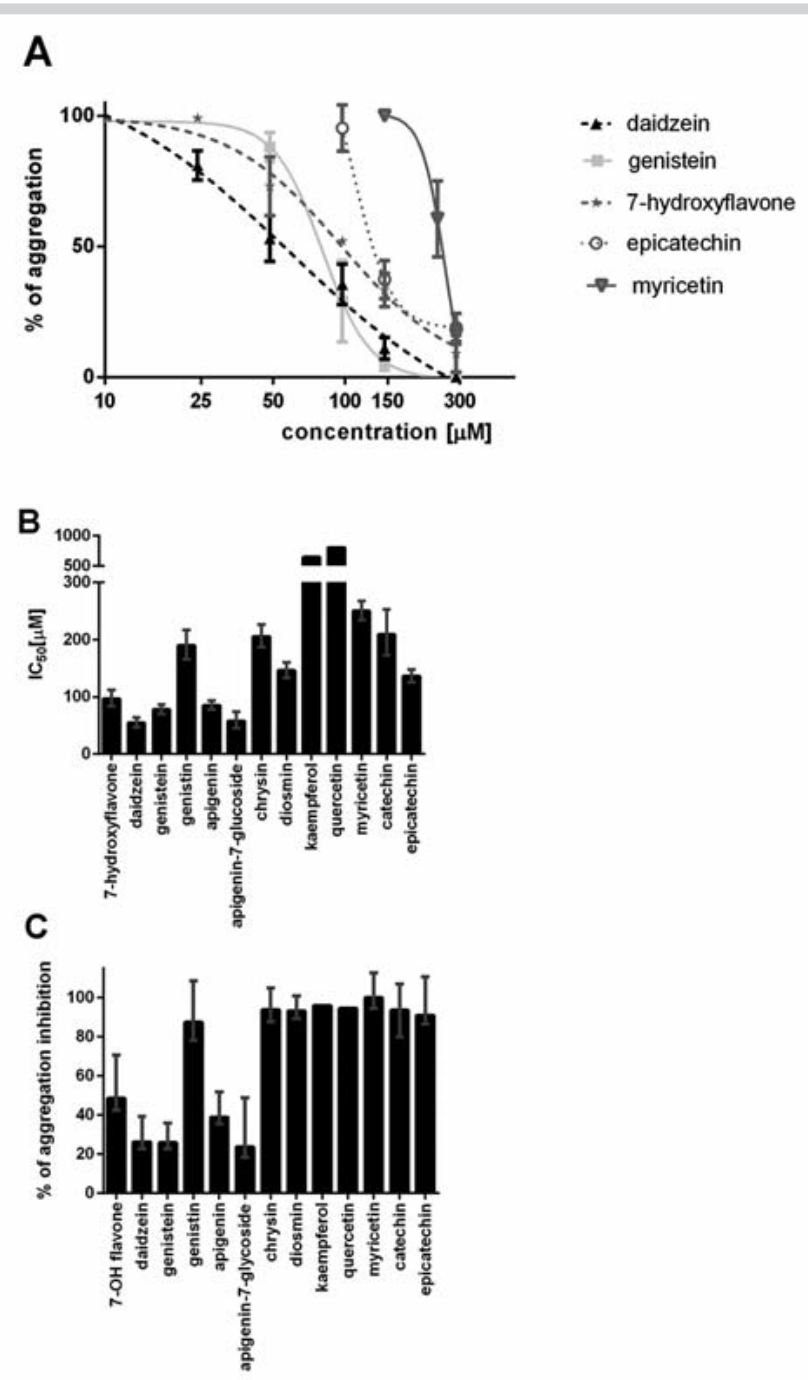

Fig. 4 Inhibition of human platelet aggregation induced by thromboxane agonist U-46619 by flavonoids. A Examples of antiaggregatory curves of three active (iso)flavonoids (7-hydroxyflavone, daidzein and genistein), moderately active epicatechin and slightly active myricetin. Comparison of $\mathrm{IC}_{50}$ values (B) and the percentage of the anti-aggregatory effect at a concentration of $100 \mu \mathrm{M}$ (C) of flavonoids which had some effect on U-46619 induced aggregation (according to $\odot$ Table 1 ). IC $\mathrm{I}_{50}$ of slightly active flavonoids (kaempferol and quercetin) were only assessed, naringenin is not shown since the calculation of an $\mathrm{IC}_{50}$ failed.

\section{Discussion}

$\nabla$

Several epidemiological studies have suggested protective effects of flavonoids against cardiovascular diseases. These effects may be linked to their influence on platelets as can be implied from the lower incidence of ischaemic stroke observed with increasing flavonoid consumption [16-21]. Although positive effects of flavonoids in experimental models of thrombosis have been documented in animal studies [22,23], clinical data are still missing and the few available small human studies have reported no effect of flavonoids on platelet aggregation in healthy volunteers $[12,24,25]$. Thus the current knowledge does not enable an unambiguous conclusion. In particular, the following issues should be considered: 1) epidemiological data are based on a food questionnaire, such estimates of flavonoid consumption represent a very imprecise indicator of flavonoid plasma levels and in addition, patient medication cannot be analyzed in detail, 2) small clinical evaluations have been performed on healthy volunteers and the fact that flavonoid consumption has not modified normal human platelet aggregation can be considered as a positive fact, 3 ) there is high variability in flavonoids pharmacokinetics and, as well, pharmacodynamic effects [3]. The variation in response to the thromboxane receptor agonists was observed in our study too, notwithstanding PRP from different donors was normalized to the same platelet concentration. Moreover, artificial animal models of platelet thrombus injuries may not sufficiently mimic the clinical situation.

Data from ex vivo and in vitro studies are much more convincing. A number of known flavonoids has been shown to possess antiplatelet effects $[3,6,8,9]$. Although many mechanisms, including inhibition of phospholipase $\mathrm{A}_{2}$, phosphodiesterases and/or protein kinases, have been reported [12,26-29], the mechanism of action, which seems to be common for the majority of flavonoids and in some of them within the range of achievable plasma concentrations, appears to be the inhibition of the AA-based pathway of platelet aggregation $[10,14]$. Indeed, flavonoids are able to decrease aggregation stimulated by different inducers. Particularly, flavonoids seem to be potent inhibitors of aggregation caused not only by AA, but also by collagen, which is known to play the key role in phase 1 of (patho)physiological platelet aggregation [30]. In addition, certain flavonoids, rather at higher concentrations, may block aggregation induced by ADP or thrombin [8], because the AA-based pathway is only one part of the complex mechanism of platelet activation evoked by endogenous signal molecules mentioned above. However, as described earlier, it is reasonable to think that several flavonoids may possess additional effects on platelet aggregation beyond their influence on the AA-based pathway due to the structural diversity of this group. 


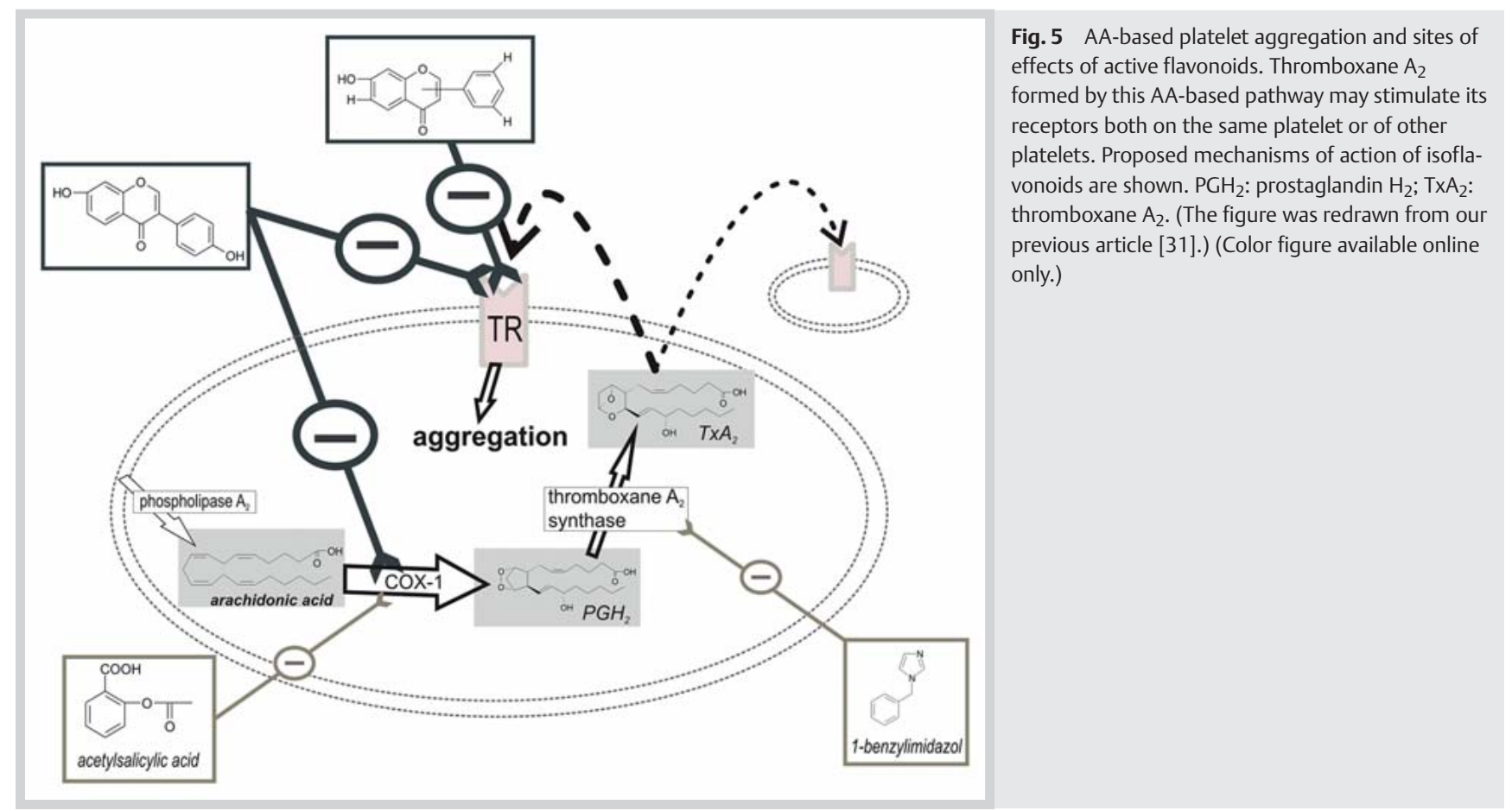

In this study we concentrated on the AA-based pathway which plays likely the key role in the effect of a majority of flavonoids. AA is, through a two-enzyme mediated reaction (COX-1 and thromboxane $A_{2}$ synthase), transformed into a potent platelet aggregation inducer, thromboxane $A_{2}$, which stimulates its own receptors, resulting in platelet aggregation. We have critically assessed the effects of flavonoids on all three levels of the AA-based aggregation cascade. Similarly to our recent study, where we have shown that some coumarins may affect two steps in this cascade [31], we documented that the isoflavonoids genistein and daidzein acted both as inhibitors of COX-1 and as functional antagonists at thromboxane $\mathrm{A}_{2}$ receptors. In addition, a number of flavonoids are able to act as thromboxane receptor antagonists ( Fig. 5). On the contrary, although three flavonoids were able to block thromboxane $A_{2}$ synthase, the concentration necessary for this effect seems to be too high and thus it is very likely that inhibition of thromboxane $A_{2}$ synthase by flavonoids has no clinical importance. One may speculate that the functional antagonism at the thromboxane $A_{2}$ receptors was achieved in this study with rather high concentrations of flavonoids. This is true, but that assay uses a high concentration of the thromboxane $\mathrm{A}_{2}$ receptor agonist U-46619 as well, which is a stable compound when comparing to very unstable endogenous thromboxane $A_{2}$. The stability aspect might be important. Even a transient weak blockade of thromboxane $A_{2}$ receptors by flavonoids might hinder the aggregation caused by thromboxane $A_{2}$ because of its rapid metabolism. In contrast, in the case of U-46619, a competition between this stable agonist and flavonoids may take place for the receptors. In the literature, there are few reports showing that flavonoids may influence the formation of thromboxane $A_{2}$ and act as functional antagonists at the thromboxane $A_{2}$ receptors $[8,9]$. Interestingly, in washed platelets, some flavonoids were able to block thromboxane $A_{2}$ formation from $A A$ in $\mu \mathrm{M}$ concentrations [8]. This result is not easily explainable since other studies have found substantial inhibitory effect of flavonoids only at higher concentrations $[9,11,32]$. It is known that the antiplatelet effect in washed platelets can be achieved in lower concentrations than in PRP [11] and interindividual differences cannot be excluded either. The latter can be supported by this study where genistein and daidzein reached partial inhibition of human platelet COX-1 at lower concentrations than in the case of the recombinant ovine COX-1 enzyme, and also by another study, where quercetin blocked COX-1 from bovine platelets with an $\mathrm{IC}_{50}$ of $8 \mu \mathrm{M}$ [33]. It should also be mentioned that the activation of isolated rat peritoneal leucocytes with ionophore A23187 leads to thromboxane $\mathrm{A}_{2}$ formation, which may be inhibited by several flavonoids at very low concentrations as well [34,35], but here, flavonoids seemed to act upstream of the AA metabolism.

As far as we know, no results on the direct inhibition of thromboxane $A_{2}$ synthase by flavonoids have been published. One possible reason is the lack of an effect and ensuing difficulties in the publication of negative data. Older reports suggested that flavonoids decrease thromboxane $\mathrm{A}_{2}$ levels indirectly mainly by inhibition of COX-1 in line with our data [32]. The available data on COX-1 inhibition are more in accordance with this study and with previous reports. In a study comparing the effect of different flavonoids and isoflavonoids in microsomal suspension of COX-1, genistein was the most active. Interestingly, daidzein was markedly less active, but its IC $_{50}$ was still lower than that of ASA [36]. The essential structural features for both activities are reported here for the first time ( Fig. 5). For COX-1 inhibition, an isoflavone ring with a 7-hydroxyl group was necessary, while for being an antagonist at thromboxane $A_{2}$ receptors, the free 7-hydroxyl group is not absolutely needed, since its blockade in apigenin-7glucoside did not abolish the effect. On the other hand, the presence of glucose at position 7 in isoflavones (genistin vs. genistein) decreased the effect. The position of ring $\mathrm{B}$ (isoflavones vs. corresponding flavones) is important for inhibition of COX-1 but not for antagonism at thromboxane receptors, where there was insignificant difference between isoflavone genistein and the corresponding flavone apigenin. The catechol ring $B$, absence of the 4-keto group or the 2,3-double bond and the presence of the 3- 
or 6-hydroxyl group were factors decreasing the activity. It is not known if effects on both levels of the AA-aggregation pathway might be an advantage, because apigenin and genistein were similarly active in a majority of studies. The superiority of the antiplatelet effect of apigenin and genistein over other flavonoids has been reported previously $[9,15,25,26,37]$. On the other hand, one study did not find any effect of apigenin on platelet aggregation [11].

Although in vitro and ex vivo data appear to support epidemiological studies, the way to the final confirmation of a positive effect of flavonoids on platelet aggregation and its effects in pathological conditions needs additional studies. In particular, when analyzing the influence of flavonoids on humans in ex vivo or in vitro conditions, one of the most important sources of errors is to overlook the pharmacokinetics of flavonoids. There are three major kinetic factors: firstly, the oral bioavailability of flavonoids is low; secondly, the absorption of non-cleaved flavonoids leads to a conjugation mainly with glucuronic acid and sulphate; and third, non-absorbed flavonoids are cleaved by intestinal bacteria into phenolic acids which may have a relevant effect on the human being as well [37]. The outcome is that the oral administration of flavonoids results in a very low concentration of total noncleaved flavonoids in the plasma in the $\mu \mathrm{M}$ range at maximum, and the concentration of unconjugated or non-metabolized flavonoids may be negligible. This clearly does not mean that flavonoids cannot have clinical effects, but that the transfer of in vitro and ex vivo data into the clinical setting has to be critically evaluated. Interpretation may be additionally complicated by human deconjugation enzymes in tissues. For quercetin, the concentrations of free aglycone may be higher in tissue than in plasma $[38,39]$.

Another interesting finding is that the derivation of the free 7-hydroxyl group with a sugar moiety did not decrease the antagonistic effect on thromboxane $A_{2}$ receptors in the case of apigenin. This result was surprising, therefore we repeated the experiments with platelets from two additional donors but the results were essentially similar. This fact is quite important from two aspects. First, it suggests that flavonoids were acting directly on the receptor because the duration of the sample incubation for the thromboxane receptor assay was only 2 minutes. Hence, it is not highly probable that a glucoside easily penetrates into platelets or is rapidly and very efficiently metabolized into the aglycone. Secondly, this may implicate that human metabolism phase II (conjugation of flavonoids) could not abolish the effect of the flavonoids because the chemical difference between glucuronic acid and glucose is not substantial. At this moment, we do not have in vivo data supporting this hypothesis, in particular due to only limited number of flavonoids human metabolites available commercially as conjugates with a glucuronic acid and/or a sulphate. This hypothesis needs to be tested in future. Interestingly, the presence of a glucose unit at C-7 of genistein reduced the effect, but did not completely abolish it. Therefore, the interaction of the receptor with flavonoids appeared to be very specific. This is emphasized by the fact that 7-hydroxyflavone and apigenin were very active, but chrysin, possessing a similar structure to apigenin but lacking the 4'-hydroxyl group, was only moderately active. As expected, the addition of a hydroxyl group in position 6 fully abolished the effect. The same is true for the introduction of another hydroxyl group in ring B (luteolin vs. apigenin).

In conclusion, this study confirmed the previous finding that flavonoids can affect platelet aggregation through the AA-based pathway. Their effect seems to be mediated mainly by antago- nism on thromboxane $A_{2}$ receptors. No clinically relevant inhibition of thromboxane $A_{2}$ synthase is suggested. Genistein and daidzein from the isoflavone subgroup blocked COX-1 as well and their effect was partly comparable to that of ASA. Since both above mentioned isoflavones are common components of the human diet, in particular in people consuming soy products, they may have a positive impact on human platelet aggregation and thus on cardiovascular diseases associated with enhanced platelet activity.

\section{Materials and Methods}

\section{$\nabla$}

\section{Materials}

AA was purchased from Chrono-Log Co. and sodium citrate solution from Biotika. Thromboxane $\mathrm{B}_{2}$ EIA kit, prostaglandin $\mathrm{H}_{2}$, U46619 and the COX inhibitor screening assay kit were purchased from Cayman Chemical Company. Genistin and apigenin-7-glucoside were purchased from Extrasynthese. Mosloflavone and negletein were synthesized by a convergent synthesis starting from chrysin according to the previous report [40] at the Sapienza University of Rome. All other flavonoids (minimal purity of 95\%, O Fig. 1), DMSO, EDTA, 1-benzylimidazole (99\% purity), indomethacin (>99\% purity) and ASA (>99\% purity) were purchased from Sigma-Aldrich. 96\% ethanol was purchased from Penta.

Blood samples from 31 healthy non-smoking volunteers were collected by venipuncture into plastic disposable syringes containing $3.8 \%$ sodium citrate $(1: 9, \mathrm{v} / \mathrm{v})$. For mechanistic experiments, the COX inhibitor indomethacin, or the thromboxane synthase inhibitor 1-benzylimidazol, were immediately added to the collected blood at a final concentration of $10 \mu \mathrm{M}$. All volunteers were health-workers who had not taken any drug for at least 14 days before the blood collection and who had given informed consent for the study. The study was performed under the supervision of the Ethical Committee of Charles University in Prague, Faculty of Pharmacy in Hradec Králové (approval date: November 12, 2012) and conforms to the Declaration of Helsinki.

PRP was obtained as a supernatant by centrifugation of the collected blood for $10 \mathrm{~min}$ at $500 \mathrm{~g}$ (centrifuge MPW-360, MPW Med. Instruments). Platelet poor plasma was prepared by centrifugation of the remaining blood for $10 \mathrm{~min}$ at $2,500 \mathrm{~g}$. The platelet count was determined using a BD Accuri C6 flow cytometer equipped with BD CFlow Software and adjusted to 2.5 or $3.5 \times 10^{8}$ platelets $/ \mathrm{mL}$ according to the planned protocol with the use of autologous plasma.

\section{Cyclooxygenase- 1 inhibition}

A commercial set from Cayman Chemicals [41], which does not give false positive results for antioxidants, was used for the evaluation of COX-1 inhibition.

Shortly, ASA or flavonoids dissolved in DMSO (final concentration of DMSO was $2 \% \mathrm{v} / \mathrm{v}$ ) were incubated with ovine COX-1 at $37^{\circ} \mathrm{C}$ and $\mathrm{AA}$ (final concentration of $100 \mu \mathrm{M}$ ) was added to the mixture to start the reaction. The formed prostaglandin $\mathrm{H}_{2}$ was measured following its reduction to prostaglandin $\mathrm{F}_{2 \alpha}$ by stannous chloride and assessed by enzyme immunoassay. The percentage of inhibition was related to the positive control with DMSO. Analogously, in additional experiments, PRP with a platelet concentration of $3.5 \times 10^{8}$ per $\mathrm{mL}$ pretreated with 1 -benzylimidazol, to block further metabolism of prostaglandin $\mathrm{H}_{2}$, was used instead of ovine COX-1 for testing of inhibition of human COX-1. 


\section{Thromboxane $A_{2}$ synthase inhibition}

Thromboxane $A_{2}$ synthase inhibition was evaluated according to the method of Chang et al. [42], with minor modifications. PRP containing indomethacin with a platelet concentration of $3.5 \times 10^{8}$ per $\mathrm{mL}$ was incubated with the tested compounds for $3 \mathrm{~min}$ at $37^{\circ} \mathrm{C}$. After addition of prostaglandin $\mathrm{H}_{2}(50 \mathrm{ng})$, the mixture was incubated for $5 \mathrm{~min}$. The incubation was immediately terminated by addition of chilled EDTA $(2 \mathrm{mM})$ and the solution was centrifuged at $10,500 \mathrm{~g}$ for $2 \mathrm{~min}$ (centrifuge MPW-52, MPW Med. Instruments). The thromboxane $B_{2}$ levels in the supernatant were measured using a thromboxane $B_{2}$ EIA kit according to the instructions of the manufacturer.

\section{Antagonism at the thromboxane receptors}

Antagonism at the thromboxane $A_{2}$ receptors was performed by turbidimetry using a Chrono-log 500-Ca aggregometer connected to a computer (Aggro/Link software, Chrono-Log Co) according to a previously reported method [31]. The turbidities of PRP and platelet poor plasma were measured as the controls. In brief, PRP ( $500 \mu \mathrm{l}, 2.5 \times 10^{8}$ per $\left.\mathrm{mL}\right)$ was pipetted into a siliconized glass cuvette and stirred at $1,000 \mathrm{rpm}$ with a magnetic stirrer at $37^{\circ} \mathrm{C}$ for $2 \mathrm{~min}$ in the aggregometer. The tested flavonoids, as well as the standard drugs, were dissolved in DMSO to obtain a $10 \%$ $(w / v)$ concentration. $5 \mu \mathrm{L}$ of a tested compound were then added to the reaction mixture at various concentrations to obtain the concentration-response curves. Individual samples were incubated at $37^{\circ} \mathrm{C}$ for $2 \mathrm{~min}$. After the incubation period, platelet aggregation was induced by the addition of U-46619, a stable agonist of thromboxane $A_{2}$ receptors. The aggregation process was monitored for $5 \mathrm{~min}$.

\section{Statistical analysis}

The differences between compounds were assessed by one-way ANOVA followed by Tukey multiple comparison test. The differences between concentration-effect curves were analyzed by use of $95 \%$ confidence intervals. The percent inhibition of aggregation at a concentration of $100 \mu \mathrm{M}\left(\mathrm{Y}_{100 \mu \mathrm{M}}\right)$ was calculated according to the following formula:

$\mathrm{Y}_{100 \mu \mathrm{M}}=\frac{\max +(100-\max )}{1+10^{\left(\log \mathrm{I} \mathrm{C}_{50}-\log 100\right) * \text { slope }}}$

where max is the maximal inhibition of platelet aggregation expressed as per cent of platelet aggregation, slope is the slope of the curve. $\mathrm{IC}_{50}$ has the common meaning.

\section{Acknowledgements}

This study was supported by the grant of the Czech Science Foundation (project No. P303/12/G163). M. .̌. would like to thank Charles University in Prague (No. SVV 260 064). Special thanks to all volunteers donating their blood for this study. We would like to thank Dr. Ilaria Proietti Silvestri and Dr. Paolo Bovicelli for synthetizing mosloflavone and negletein as well.

\section{Conflict of Interest}

$\nabla$

Authors declare no conflict of interest.
References

1 Michelson AD. Platelets, 2nd edition. Amsterdam: Academic Press (Elsevier); 2007

2 Hsiao G, Ko FN, Jong TT, Teng CM. Antiplatelet action of 3',4'-diisovalerylkhellactone diester purified from Peucedanum japonicum Thunb. Biol Pharm Bull 1998; 21: 688-692

3 Mower RL, Landolfi R, Steiner M. Inhibition in vitro of platelet aggregation and arachidonic acid metabolism by flavone. Biochem Pharmacol 1984; 33: 357-363

4 Pilgrim T, Windecker $S$. Antiplatelet therapy for secondary prevention of coronary artery disease. Heart 2014; 100: 1750-1756

5 Kontogiorgis C, Hadjipavlou-Litina D. Thromboxane synthase inhibitors and thromboxane A2 receptor antagonists: a quantitative structure activity relationships (QSARs) analysis. Curr Med Chem 2010; 17: 31623214

6 Kim JM, Yun-Choi HS. Anti-platelet effects of flavonoids and flavonoidglycosides from Sophora japonica. Arch Pharm Res 2008; 31: 886-890

7 Bojic M, Debeljak Z, Tomicic M, Medic-Saric M, Tomic S. Evaluation of antiaggregatory activity of flavonoid aglycone series. Nutrition journal 2011; 10: 73

8 Tzeng SH, Ko WC, Ko FN, Teng CM. Inhibition of platelet aggregation by some flavonoids. Thromb Res 1991; 64: 91-100

9 Guerrero JA, Lozano ML, Castillo J, Benavente-Garcia O, Vicente V, Rivera $J$. Flavonoids inhibit platelet function through binding to the thromboxane A2 receptor. J Thromb Haemost 2005; 3: 369-376

10 Mladenka P, Zatloukalova L, Filipsky T, Hrdina R. Cardiovascular effects of flavonoids are not caused only by direct antioxidant activity. Free Radic Biol Med 2010; 49: 963-975

11 Kelly C, Hunter K, Crosbie L, Gordon MJ, Dutta-Roy AK. Modulation of human platelet function by food flavonoids. Biochem Soc Trans 1996; 24 : $197 \mathrm{~S}$

12 Hubbard GP, Stevens JM, Cicmil M, Sage T, Jordan PA, Williams CM, Lovegrove JA, Gibbins JM. Quercetin inhibits collagen-stimulated platelet activation through inhibition of multiple components of the glycoprotein VI signaling pathway. J Thromb Haemost 2003; 1: 1079-1088

13 Fuentes E, Palomo M. Antiplatelet effects of natural bioactive compounds by multiple targets: Food and drug interactions. J Funct Foods 2014; 6: 73-81

14 Navarro-Nunez L, Castillo J, Lozano ML, Martinez C, Benavente-Garcia O, Vicente $V$, Rivera J. Thromboxane A2 receptor antagonism by flavonoids: structure-activity relationships. J Agric Food Chem 2009; 57 : 1589-1594

15 Navarro-Nunez L, Lozano ML, Palomo M, Martinez C, Vicente V, Castillo J, Benavente-Garcia O, Diaz-Ricart M, Escolar G, Rivera J. Apigenin inhibits platelet adhesion and thrombus formation and synergizes with aspirin in the suppression of the arachidonic acid pathway. J Agric Food Chem 2008; 56: 2970-2976

16 Hertog MG, Feskens EJ, Hollman PC, Katan MB, Kromhout D. Dietary antioxidant flavonoids and risk of coronary heart disease: the Zutphen Elderly Study. Lancet 1993; 342: 1007-1011

17 Keli SO, Hertog MG, Feskens EJ, Kromhout D. Dietary flavonoids, antioxidant vitamins, and incidence of stroke: the Zutphen study. Arch Intern Med 1996; 156: 637-642

18 Knekt P, Kumpulainen J, Jarvinen R, Rissanen H, Heliovaara M, Reunanen A, Hakulinen T, Aromaa A. Flavonoid intake and risk of chronic diseases. Am J Clin Nutr 2002; 76: 560-568

19 Geleijnse JM, Launer LJ, Van der Kuip DA, Hofman A, Witteman JC. Inverse association of tea and flavonoid intakes with incident myocardial infarction: the Rotterdam Study. Am J Clin Nutr 2002; 75: 880-886

20 McCullough ML, Peterson JJ, Patel R, Jacques PF, Shah R, Dwyer JT. Flavonoid intake and cardiovascular disease mortality in a prospective cohort of US adults. Am J Clin Nutr 2012; 95: 454-464

21 Mursu J, Voutilainen S, Nurmi T, Tuomainen TP, Kurl S, Salonen JT. Flavonoid intake and the risk of ischaemic stroke and CVD mortality in middle-aged Finnish men: the Kuopio ischaemic heart disease risk factor study. Br J Nutr 2008; 100: 890-895

22 Mosawy S, Jackson DE, Woodman OL, Linden MD. Treatment with quercetin and 3',4'-dihydroxyflavonol inhibits platelet function and reduces thrombus formation in vivo. J Thromb Thrombolysis 2013; 36: 50-57

23 Gryglewski RJ, Korbut R, Robak J, Swies J. On the mechanism of antithrombotic action of flavonoids. Biochem Pharmacol 1987; 36: 317-322

24 Conquer JA, Maiani G, Azzini E, Raguzzini A, Holub BJ. Supplementation with quercetin markedly increases plasma quercetin concentration 
without effect on selected risk factors for heart disease in healthy subjects. J Nutr 1998; 128: 593-597

25 Janssen K, Mensink RP, Cox FJ, Harryvan JL, Hovenier R, Hollman PC, Ka$\tan M B$. Effects of the flavonoids quercetin and apigenin on hemostasis in healthy volunteers: results from an in vitro and a dietary supplement study. Am J Clin Nutr 1998; 67: 255-262

26 Wright B, Moraes LA, Kemp CF, Mullen W, Crozier A, Lovegrove JA, Gibbins JM. A structural basis for the inhibition of collagen-stimulated platelet function by quercetin and structurally related flavonoids. $\mathrm{Br}$ J Pharmacol 2010; 159: 1312-1325

27 Guerrero JA, Navarro-Nunez L, Lozano ML, Martinez C, Vicente V, Gibbins $J M$, Rivera J. Flavonoids inhibit the platelet $\operatorname{TxA}(2)$ signalling pathway and antagonize $\mathrm{TxA}(2)$ receptors (TP) in platelets and smooth muscle cells. Br J Clin Pharmacol 2007; 64: 133-144

28 Lindahl M, Tagesson C. Flavonoids as phospholipase A2 inhibitors: importance of their structure for selective inhibition of group II phospholipase A2. Inflammation 1997; 21: 347-356

29 Beretz A, Stierle A, Anton R, Cazenave JP. Role of cyclic AMP in the inhibition of human platelet aggregation by quercetin, a flavonoid that potentiates the effect of prostacyclin. Biochem Pharmacol 1981; 31: 3597-3600

30 Jackson SP. The growing complexity of platelet aggregation. Blood 2007; 109: 5087-5095

31 Macakova K, Rehakova Z, Mladenka P, Karlickova J, Filipsky T, Riha M, Prasad AK, Parmar VS, Jahodar L, Pavek P, Hrdina R, Saso L. In vitro platelet antiaggregatory properties of 4-methylcoumarins. Biochimie 2012; 94: 2681-2686

32 Corvazier E, MacloufJ. Interference of some flavonoids and non-steroidal anti-inflammatory drugs with oxidative metabolism of arachidonic acid by human platelets and neutrophils. Biochim Biophys Acta 1985; 835: 315-321

33 Chi YS, Jong HG, Son KH, Chang HW, Kang SS, Kim HP. Effects of naturally occurring prenylated flavonoids on enzymes metabolizing arachidonic acid: cyclooxygenases and lipoxygenases. Biochem Pharmacol 2001; 62: 1185-1191

34 Laughton MJ, Evans PJ, Moroney MA, Hoult JR, Halliwell B. Inhibition of mammalian 5-lipoxygenase and cyclo-oxygenase by flavonoids and phenolic dietary additives. Relationship to antioxidant activity and to iron ion-reducing ability. Biochem Pharmacol 1991; 42: 1673-1681

35 Moroney MA, Alcaraz MJ, Forder RA, Carey F, Hoult JR. Selectivity of neutrophil 5-lipoxygenase and cyclo-oxygenase inhibition by an anti-inflammatory flavonoid glycoside and related aglycone flavonoids. J Pharm Pharmacol 1988; 40: 787-792

36 Wang H, Nair MG, Strasburg GM, Booren AM, Gray I, Dewitt DL. Cyclooxygenase active bioflavonoids from Balaton tart cherry and their structure activity relationships. Phytomedicine 2000; 7: 15-19

37 Kim DH, Jung EA, Sohng IS, Han JA, Kim TH, Han MJ. Intestinal bacterial metabolism of flavonoids and its relation to some biological activities. Arch Pharm Res 1998; 21: 17-23

38 Williamson $\mathrm{G}$. The use of flavonoid aglycones in in vitro systems to test biological activities: based on bioavailability data, is this a valid approach? Phytochem Rev 2002; 1: 215-222

39 Bieger J, Cermak R, Blank R, de Boer VC, Hollman PC, Kamphues J, Wolffram $S$. Tissue distribution of quercetin in pigs after long-term dietary supplementation. J Nutr 2008; 138: 1417-1420

40 Righi G, Antonioletti R, Proietti Silvestri I, D'Antona N, Lambusta D, Bovicelli $P$. Convergent synthesis of mosloflavone, negletein and baicalein from crysin. Tetrahedron Lett 2010; 66: 1294-1298

41 Cayman Chemical Company COX Inhibitor Screening Assay Kit. Available at http://www.caymanchem.com/app/template/Product.vm/cata$\log / 560131$. Accessed January 6, 2012.

42 Chang TS, Kim HM, Lee KS, Khil LY, Mar WC, Ryu CK, Moon CK. Thromboxane A2 synthase inhibition and thromboxane A2 receptor blockade by 2-[(4-cyanophenyl)amino]-3-chloro-1,4-naphthalenedione (NQY15) in rat platelets. Biochem Pharmacol 1997; 54: 259-268 